\title{
RUPTURED ADRENAL CYST
}

\author{
J. O. R. Stewart, M.B., F.R.C.S. \\ Senior Surgical Registrar \\ J. G. Lester, M.B., F.R.C.S. \\ Surgical Registrar
}

Addenbrooke's Hospital, Cambridge

ADRENAL cysts are uncommon. The majority are of minute size and are found only at post-mortem examination. Cysts large enough to present clinically are rarely seen (O'Connell, 1959). The occurrence of a very large specimen and its subsequent rupture to present as an acute abdominal emergency is therefore of interest.

\section{Case History}

A female, aged 60, was admitted as an emergency. Six hours previously she had been seized with sudden left-sided abdominal pain which gradually spread centrally towards the umbilicus. There were no backache, nausea, vomiting or other symptoms.

On examination, she was pale and anxious with subnormal temperature and pulse rate of $68 /$ minute. There was upper abdominal distension and acute tenderness, most marked on the left side. A large firm irregular mass occupied the left hypochondrium and the left flank. It resembled an enlarged spleen. There were no bowel sounds. The other systems presented no noteworthy abnormalities.

Investigations. Plasma amylase, 99 units $/ 100 \mathrm{ml}$. Plain X-ray of the abdomen showed a large soft-tissue mass in the left upper abdomen containing some calcified areas. Blood count: Hb. 10.7 g./100 ml., leucocytes $12,000 /$ c.mm., film-no abnormality.

It was considered that the patient had either a perforation of a large tumour of the stomach or an infarct in an enlarged spleen. Laparotomy through a left upper paramedian incision showed free clear fluid in the peritoneal cavity. The epigastric tumour was found to be a normal spleen pushed forward by a very large retroperitoneal mass in the left upper abdomen.

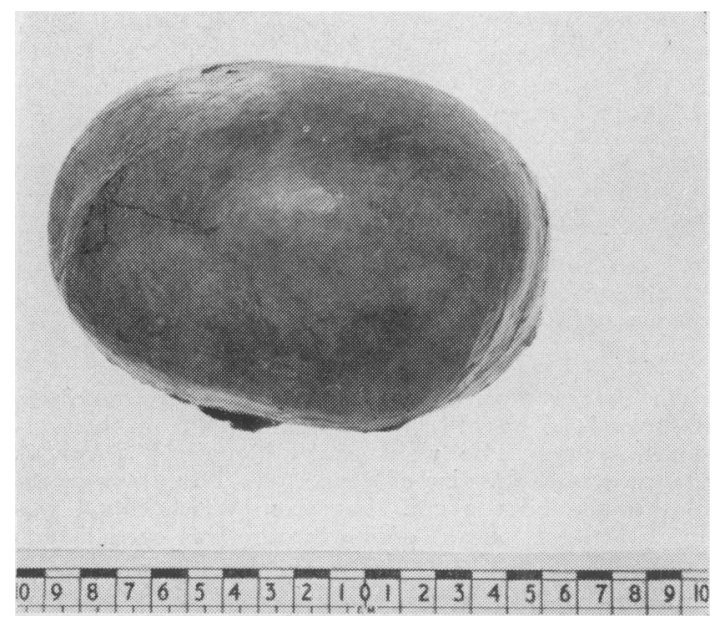

FIG. I.-Encapsulated cyst of the adrenal gland.
The tumour mass lay in front of and above the kidney, which was depressed by it. It had a tough fibrous capsule with a longitudinal split on its posterior surface, from which blood and clot exuded, causing a retroperitoneal hæmorrhage. It was mobilized easily from the surrounding tissues and removed after a short narrow pedicle on the medial side had been secured.

The patient had an uneventful post-operative course and was discharged on the $14^{\text {th }}$ post-operative day.

Pathology (Figs. I and 2). Macroscopically the fresh specimen measured $20 \times 17 \times 10 \mathrm{~cm}$. It had a welldemarcated firm grey capsule, I to $2 \mathrm{~mm}$. thick, with a linear tear $8 \mathrm{~cm}$. long posteriorly. The cut surface showed that there was an ochre-yellow line under the capsule. The rest of the mass was composed of an outer layer of old blood clot and a central mass of recent clot. Microscopically, a collagenous capsule overlay a layer of adrenal cortical tissue (the yellow layer), which surrounded blood clot of varying ages. Part of the mass included cavernous spaces, many of which contained blood; some of them at the periphery had a definite endothelial lining. The appearances were those of hæmorrhage into a suprarenal cyst of angiomatous type. It was not possible to say whether it was an hæmangioma or a lymphangioma.

\section{Comment}

The case presents several interesting features. (I) The large size of the cyst is remarkable, as adrenal cysts seldom exceed $10 \mathrm{~cm}$. in diameter (O'Connell, 1959), though larger specimens have occasionally been described (Adderley, Grime and Whitehead, 1954; Parker, 1952). (2) The occur-

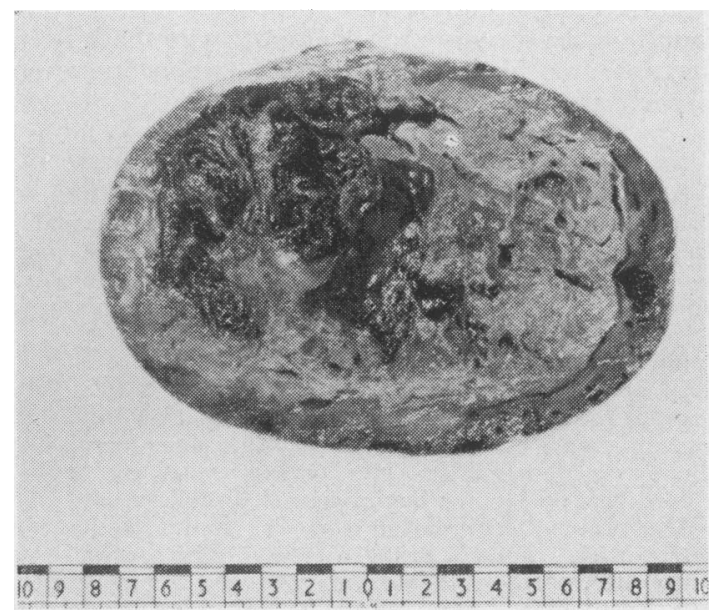

FIG. 2.-Cross-section of the cyst showing blood clot of varying age. 
rence of bleeding into the cyst and subsequent rupture to cause an acute abdominal emergency is an unusual presentation. The more common complaints are of pain in the side, swelling, malaise, anorexia or anæmia. (3) The pathological type is uncommon. The commonest cyst of the adrenal is the pseudocyst due to hæmorrhage into a diseased or normal gland. This variety has often blood clot surrounding the wall and shows no endothelial lined spaces as in the present angiomatous type. Calcification may occur in either. It is usually impossible to distinguish between lymphangiectatic cysts and cystic hæmangiomata (Adderley andz others, 1954). (4) The palpation of a normal-sizedo spleen in the epigastrium is rare, and was due to $c$ its forward displacement on the dome of a large. retroperitoneal tumour, giving the false impressionos of enlargement.

We wish to thank Mr. P. H. R. Ghey for permission to treat and publish the case, which was admitted under his care. We also thank Dr. J. H. Rack for the patho- $\overparen{\Phi}$ logical report.

\section{REFERENCES}

Adderley, C. H., Grime, R. T., and Whitehead, R. (1954): Adrenal Cysts, Brit. F. Surg., 42, 389 .

O'Connell, N. D. (1959): Adrenal Cysts, Brit. F. Radiol., 33, 490.

PARKER, D. (I952): Benign Cysts of the Adrenal Gland, $\mathscr{Y}$. Urol., 68, I.

\section{MASSIVE INTRAPERITONEAL HAEMORRHAGE FROM RUPTURED CORPUS LUTEUM CYST

\author{
Surgical Registrar
} \\ Grant Williams, M.B., B.S., F.R.C.S. \\ K. PARMar, M.B., B.S., D.R.C.O.G. House Surgeon}

Princess Alice Memorial Hospital, Eastbourne

\begin{abstract}
DuRING the process of physiological evolution of the corpus luteum, some hæmorrhage from the perifollicular blood vessels of the theca is a normal event, but massive leakage of this hæmorrhage into the peritoneal cavity is rare. Fitzgerald and Berrigan (r959) called it an 'ovarian vascular accident' and rarely is it accurately diagnosed before operation. This condition is more common than generally thought, and often small hæmorrhages from a ruptured corpus luteum or corpus luteum cyst are found at laparotomy on patients who had been diagnosed as having appendicitis-when operation is performed at mid-cycle.
\end{abstract}

\section{Case Report}

An unmarried girl, aged 17 years, was admitted to Princess Alice Hospital on 15.2.62 from the Casualty Department. She complained of sudden acute pain in the right iliac fossa and nausea. L.M.P. 30 days previously, lasting for seven days. Menstrual history: 3 to 4 days $/ 28$ days, regular.

On examination she was found to be pale, of ashengrey complexion. Pulse 92/min.; temp. $98.4^{\circ}$; B.P. $120 / 80 \mathrm{~mm}$. Hg. Abdominal examination revealed guarding and tenderness in the right iliac fossa, but there was no rigidity. Her breasts were not active. There was no hæmorrhagic vaginal discharge.

On vaginal examination she was found to have a retroverted, slightly bulky uterus. The cervix was rather soft. Her right adnexæ were extremely tender, but no definite mass could be felt. A provisional diagnosis of appendicitis was made, but the possibility of an ectopic pregnancy was kept in mind.

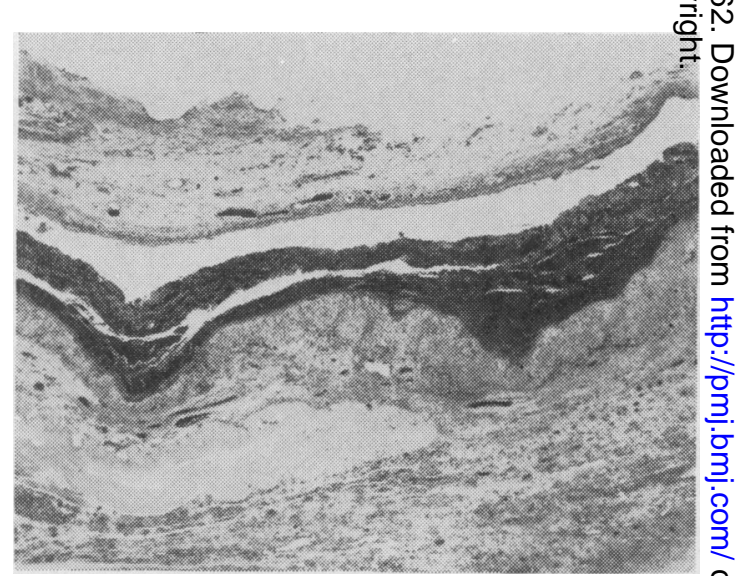

FIG. I.-Shows hæmorrhage in the cavity of corpus luteum cyst. There is also marked congestion in the perifollicular blood vessels of the theca.

On the evening of the same day laparotomy performed; $43 \mathrm{oz}$. of blood were removed from the peritoneal cavity. The right ovary contained a corpusw luteum cyst of the size of a walnut. There was a tearo in its wall about $2 \mathrm{~cm}$. long from which blood was slowly leaking. Right oophorectomy was carried out; 4 pints of blood were transfused.

A further exploration was necessary 12 hours later:? because of secondary hæmorrhage as the mesovarium was bleeding at the site of transfixion by the ligature. 